\title{
Entraves vivenciados no cotidiano da mulher soropositiva: uma análise investigativa
}

\author{
Barriers experienced in the daily lives of seropositive women: an investigative analysis
}

Barreras experimentadas en la vida diaria de las mujeres seropositivas: un análisis de investigación

Recebido: 08/11/2021 | Revisado: 15/11/2021 | Aceito: 15/11/2021 | Publicado: 25/11/2021

Fernanda Raquel Gomes Argolo

ORCID: https://orcid.org/0000-0002-1919-5878 Centro Universitário Estácio de Sergipe, Brasil

E-mail: frgargolo@gmail.com

Ana Fátima Souza Melo de Andrade

ORCID: https://orcid.org/0000-0002-7024-6175

Centro Universitário Estácio de Sergipe, Brasil

E-mail: anafatimamelo@ hotmail.com

Weber de Santana Teles

ORCID: https://orcid.org/0000-0003-1770-8278

Centro de Hemoterapia de Sergipe, Brasil

E-mail: arteecura@hotmail.com

Max Cruz da Silva

ORCID: https://orcid.org/0000-0002-6944-5986

Faculdade Pio Décimo, Brasil

E-mail: maxlfi@hotmail.com

Ruth Cristini Torres

ORCID: https://orcid.org/0000-0002-8664-192X Instituto de Hematologia e Hemoterapia de Sergipe, Brasil E-mail: ruthcristini@gmail.com

Silvia Maria da Silva Sant'ana Rodrigues

ORCID: https://orcid.org/0000-0003-2421-8701 Centro Universitário Uninassau, Brasil

E-mail: profenf.silviasantana@gmail.com

Marcel Vinícius Cunha Azevedo ORCID: https://orcid.org/0000-0002-5312-3333 Universidade Tiradentes, Brasil E-mail: marcelvinicius49@gmail.com

Aline Barreto Hora

ORCID: https://orcid.org/0000-0002-3930-6475 Centro Universitário Estácio de Sergipe, Brasil E-mail: aline.barretoh@hotmail.com

Taíssa Alice Soledade Calasans ORCID: https://orcid.org/0000-0003-0460-4437 Universidade Tiradentes, Brasil E-mail: taissa.asc@gmail.com

Ângela Maria Melo Sá Barros ORCID: https://orcid.org/0000-0003-4087-3247 Universidade Federal do Rio de Janeiro, Brasil E-mail: angelsamelo@ hotmail.com

Maria Hozana Santos Silva ORCID: https://orcid.org/0000-0001-5742-5366 Faculdade Ages de Medicina, Brasil E-mail: hosana_p@hotmail.com

Paulo Celso Curvelo Santos Junior ORCID: https://orcid.org/0000-0001-5834-6782 Universidade Tiradentes, Brasil E-mail: paulo.curvelo.jr@gmail.com

\section{Resumo}

O estudo teve por objetivo identificar os entraves sociais e assistenciais no cotidiano das mulheres soropositivas. Tratouse de uma revisão integrativa de literatura através da amostra de 18 artigos, originais, dos últimos 5 anos, selecionados nas bases de dados: Biblioteca Virtual da Saúde (BVS), Literatura Latino Americana e do Caribe em Ciências da Saúde (LILACS), Biblioteca Eletrônica Cientific Library Online (SCIELO), que se encontram em quadros sinópticos de acordo com as categorias do estudo. Os resultados evidenciaram a tristeza, a angústia, o preconceito, as mudanças no relacionamento familiar e social, a ocultação do diagnóstico e a falta de adesão ao tratamento. Constatou-se que a confirmação do HIV gera grande impacto na vida da mulher e é necessário um cuidado holístico para o enfrentamento da soropositividade. Esse estudo pode contribuir para futuras pesquisas direcionadas a melhora na assistência 
multiprofissional e na qualidade de vida das portadoras de HIV. Idealizando dessa forma uma melhora na qualidade de vida das soropositivas, na assistência multiprofissional, mais ampla, qualificada, reduzindo os entraves assistenciais e sociais.

Palavras-chave: Atenção Primária à Saúde; Cuidados de enfermagem; HIV; Mulheres.

\begin{abstract}
The study aimed to identify the social and assistance barriers in the daily lives of HIV positive women. This was an integrative literature review using a sample of 18 original articles from the last 5 years, selected from the following databases: Virtual Health Library (VHL), Latin American and Caribbean Literature on Health Sciences (LILACS), Electronic Library Scientific Library Online (SCIELO), which can be found in synoptic tables according to the study categories. The results showed sadness, anguish, prejudice, changes in family and social relationships, concealment of the diagnosis and lack of adherence to treatment. It was found that the confirmation of HIV has a great impact on women's lives and that a holistic care is needed to deal with seropositivity. This study can contribute to future research aimed at improving multidisciplinary care and quality of life for HIV carriers. Thus, idealizing an improvement in the quality of life of seropositive women, in multidisciplinary, broader, more qualified care, reducing care and social barriers.
\end{abstract}

Keywords: Primary Health Care; Nursing care; HIV; Women.

\title{
Resumen
}

El estudio tuvo como objetivo identificar las barreras sociales y asistenciales en la vida diaria de las mujeres VIH positivas. Se realizó una revisión integradora de la literatura utilizando una muestra de 18 artículos originales de los últimos 5 años, seleccionados de las siguientes bases de datos: Biblioteca Virtual en Salud (BVS), Literatura Latinoamericana y del Caribe en Ciencias de la Salud (LILACS), Biblioteca Electrónica Biblioteca Científica en Línea ( SCIELO), que se pueden encontrar en tablas sinópticas según las categorías de estudio. Los resultados mostraron tristeza, angustia, prejuicio, cambios en las relaciones familiares y sociales, ocultación del diagnóstico y falta de adherencia al tratamiento. Se encontró que la confirmación del VIH tiene un gran impacto en la vida de las mujeres y que se necesita una atención integral para hacer frente a la seropositividad. Este estudio puede contribuir a futuras investigaciones destinadas a mejorar la atención multidisciplinaria y la calidad de vida de los portadores del VIH. Así, idealizando una mejora en la calidad de vida de las mujeres seropositivas, en una atención multidisciplinar, más amplia, más calificada, reduciendo las barreras asistenciales y sociales.

Palabras clave: Atención Primaria de Salud; Cuidado de enfermera; VIH; Mujeres.

\section{Introdução}

O Vírus da Imunodeficiência Humana (HIV), é um retrovírus causador da Síndrome da Imunodeficiência Adquirida (AIDS) o qual ataca o sistema imunológico atingindo principalmente os linfócitos T CD4+, alterando o DNA das células, multiplicando-se e rompendo-os a fim de avançar a infecção. Devido a esse avanço, o sistema de defesa perde sua autonomia, tornando organismo do indivíduo mais vulnerável a doenças. A transmissão pode ocorrer por várias vias sendo a principal por relação sexual desprotegida (Brasil, 2019).

Em razão das modificações genéticas existem dois tipos de HIV, 1 e 2, o HIV tipo 1 é encontrado atualmente em todos os continentes, sendo o mais patogênico, e o HIV tipo 2 que tem ocorrência mais restrita ao continente africano. No Brasil há o predomínio do HIV-1, sendo que o registro de infecções pelo HIV tipo 2 é pouco frequente (Benchetrit et al., 2018).

O HIV pode ser transmitido através de contato sexual desprotegido, e contato direto com sangue contaminado, o que inclui compartilhamento de agulhas e de seringas, transfusão de sangue/hemoderivados e acidentes com material biológico. A transmissão também ocorre de forma vertical da mãe para o bebê durante a gestação, durante o parto ou na amamentação (Ribeiro \& Silva, 2018).

Apesar de ser uma doença ainda sem cura, com os avanços da ciência houve a introdução da Terapia de antirretrovirais (TARV) a qual começou a ser implantada no Brasil de forma gratuita em 1996 e permanece até os dias a is, possibilitando um tratamento que consiste em evitar o enfraquecimento do sistema imunológico, proporcionando uma melhor expectativa de vida para o soropositivo (Brasil, 2019).

No Brasil, houve um declínio nos casos de HIV em mulheres cujos registros de 1980 até junho de 2019 apresentaram o número de 633.462 infectadas, ou seja, 65,6\% casos de AIDS em homens e 332.505 (34,4\%) em mulheres (BRASIL, 2019b). 
No entanto, na atualidade, as mulheres possuem uma vulnerabilidade maior à infecção do HIV devido a fatores como o índice elevado de violência sexual, a coitarca cada vez mais precoce, a baixa adesão ao uso de preservativos, o uso de drogas, o histórico iminente e recorrente de Infecções Sexualmente Transmissíveis (ISTS) (Oliveira et al., 2015).

O impacto de viver com uma doença crônica modifica drasticamente a qualidade de vida do portador de HIV. Interferindo em todo o enfrentamento associado a vários obstáculos que surgem como o preconceito em âmbito familiar, social, íntimo e psicológico. Sendo essencial uma assistência universal, equânime, integral e acolhedora, tentando fornecer a esse público um convívio satisfatório com o HIV (Jesus et al., 2017).

A motivação para esse estudo surgiu ao perceber que não se tinha muito conhecimento tampouco pesquisas direcionadas às mulheres portadoras de HIV, originando, então, um interesse em conhecer e entender quais são as dificuldades diárias que as portadoras dessa doença passam ao longo da vida. Tal interesse gera uma grande importância na qualificação do atendimento dos profissionais que atuam em todos os setores da saúde que envolvam esse tema.

Diante do que foi exposto, este estudo teve como objetivo identificar, através de artigos científicos, os entraves sociais e assistenciais presentes no cotidiano das mulheres soropositivas.

\section{Metodologia}

O presente estudo trata de uma revisão integrativa que tem como finalidade reunir e sintetizar resultados de pesquisas sobre o tema investigado de maneira sistemática, ordenada e abrangente, contribuindo para o aprofundamento no conhecimento científico da temática (Ferenho \& Fernandes, 2016).

Para a elaboração do estudo foi necessário ser ordenar o mesmo em 6 etapas: 1- Identificação do tema; 2- Inserção dos critérios de inclusão e exclusão dos artigos/ busca na literatura; 3- Indagação das questões norteadoras/ categorização dos estudos baseados nos objetivos; 4- Avaliação dos artigos inclusos; 5- Tabulação das informações dos artigos escolhidos/ averiguação dos resultados; 6- Síntese do conhecimento/ apresentação da revisão (Sousa et al., 2017).

A análise dos artigos selecionados teve como questões norteadoras as seguintes perguntas: como seriam as dificuldades no cotidiano das pacientes soropositivas?; quais são os impactos desse diagnóstico na rotina delas?

Dessa forma, realizou-se uma busca online da literatura entre os meses de março a outubro de 2020, nas bases de dados da Biblioteca Virtual em Saúde- BVS, Scientific Eletronic Library Online- SCIELO, LILACS - Literatura Latino-americana e do Caribe em Ciências da Saúde, por se tratar de bases confiáveis, atualizadas e relacionadas com a área da saúde e da enfermagem. Os Descritores em Ciências da Saúde (DeCS) utilizados foram: "Cuidados de Enfermagem”, "Atenção Primária à Saúde", "HIV", "Mulheres".

A busca foi realizada em cada base usando, primeiramente o descritor "HIV", e depois ligando este através do uso de operador boleano and com "Cuidados de Enfermagem". Na base SCIELO foi usado os descritores "HIV" e "Atenção Primária à Saúde" de forma individual e sem uso de operador boleano. No LILACS foi usado o descritor "HIV" associado ao uso de operador boleano and ao descritor "Mulheres".

Foram utilizados como critérios de inclusão para delimitar esta pesquisa publicações que abordassem o objetivo do estudo, sendo, artigos originais disponibilizados gratuitamente na íntegra, nas bases de dados, publicados em português, no período dos últimos 5 anos, em consequência de que os estudos no âmbito da saúde, são bem ativos, necessitando de renovações constantes. Sendo exclusos deste estudo os manuais, monografias e artigos de revisão.

$\mathrm{Na}$ seleção das referências, foram analisados o resumo e os títulos dos artigos mais atrativos, os quais foram selecionados para o estudo de acordo com os objetivos e resultados, que mais responderam, aos critérios estabelecidos. Desse modo o estudo foi composto por uma amostra de 18 artigos que responderam aos requisitos propostos. 
Diante disso, foi elaborado pelas pesquisadoras um instrumento na forma de quadro sinóptico para coleta dos dados necessários na avaliação de cada estudo selecionado, facilitando no direcionamento da pesquisa. Contendo neste, informações sobre citação do artigo, base de dados, região/local, métodos e resultados.

O estudo ficou dividido em duas categorias: Barreiras sociais na vida das mulheres soropositivas e Dificuldades assistenciais às mulheres portadoras de HIV. Trabalhou-se os resultados em gráficos e quadros, sendo possível dessa forma organizar todos os artigos que se adequaram as categorias.

A análise bibliográfica foi redigida de acordo com as normas da NBR 10520, para a forma de apresentação das citações, a NBR 6023 que determina a forma correta das referências, e a Lei dos direitos autorais 12.853/13 que dispõe em seu Art. $1^{\circ}$. Esta Lei executa os direitos autorais, entendendo se sob esta denominação os direitos de autor e os que lhes são conexos (ABNT, 2002).

\section{Resultados}

Após levantamento bibliográfico das produções nacionais no período compreendido entre 2015 a 2020, a realização do cruzamento das palavras-chave, resultando o total de 781 artigos, dos quais 202 artigos foram retirados para revisão de texto completo e 18 artigos atenderam os critérios para inclusão na revisão, posteriormente sendo organizados de acordo com as denominações do quadro sinóptico.

Foi possível observar que em relação ao período de publicação, o ano que apresentou maior número de artigos publicados foi no ano de 2019 com 5 publicações, em seguida 2017 e 2015 com 4 cada, em seguida 2018 com 3 , e os anos de 2020 e 2016 com 1 respectivamente, como demonstrado no Gráfico 1.

Gráfico 1 - Resultados dos estudos em relação ao período de publicação, Aracaju/SE.

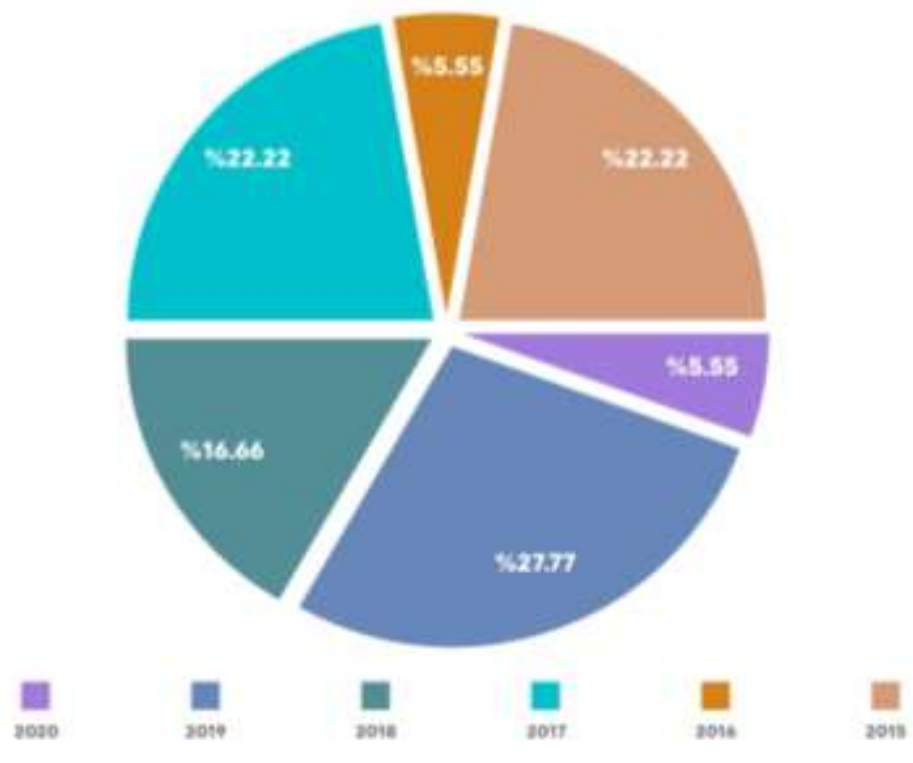

Fonte: Autores (2021).

Dos artigos que formaram a amostra desta revisão integrativa, a maioria originou-se da base de dados LILACS contendo 8, seguido do BVS e SCIELO com o mesmo quantitativo, ou seja, 5 cada, como demonstrado no Quadro 1. 
Research, Society and Development, v. 10, n. 15, e232101522973, 2021

(CC BY 4.0) | ISSN 2525-3409 | DOI: http://dx.doi.org/10.33448/rsd-v10i15.22973

Quadro 1 - Distribuição dos artigos científicos obtidos segundo bases de dados, Aracaju/SE.

\begin{tabular}{|c|c|}
\hline Base de Dados & Quantidade de estudos \\
\hline BVS & 05 \\
\hline SCIELO & 05 \\
\hline LILACS & 08 \\
\hline
\end{tabular}

Fonte: Autores (2021).

De acordo com a distribuição dos artigos relacionando o quantitativo por região, foram encontrados 9 estudos publicados no Sudeste onde obteve a maior quantidade, seguido do nordeste com 5, sul e norte com 3 respectivamente e do centro-oeste contendo 2, assim elencados no Gráfico 2.

Gráfico 2 - Distribuição dos artigos científicos obtidos por região, Aracaju/SE.

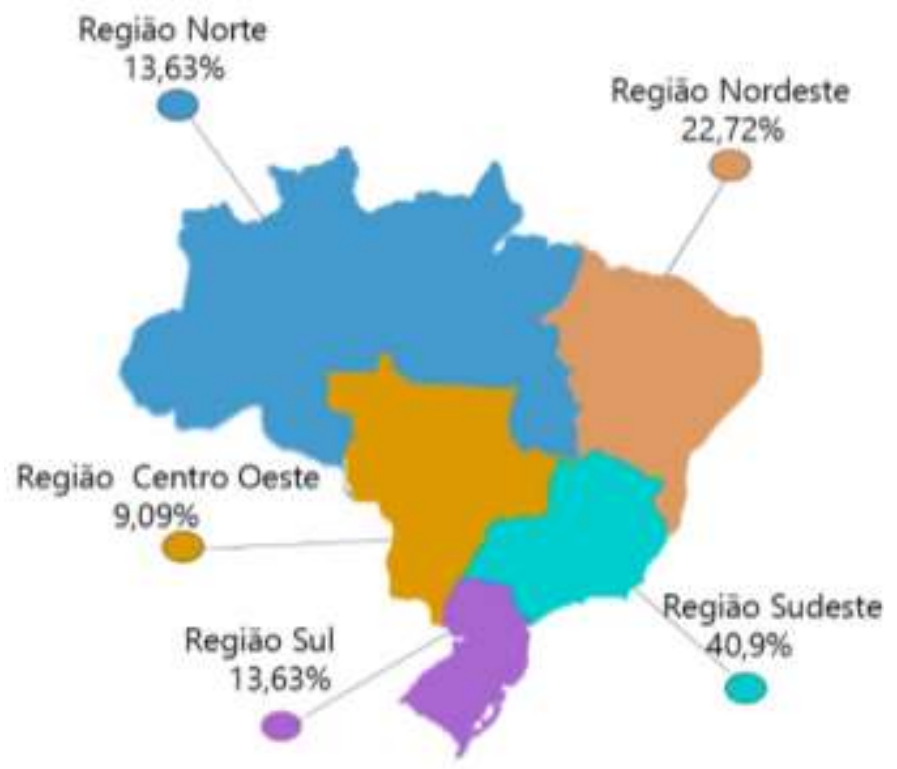

Fonte: Autores (2021).

Nos quadros 2 e 3, estão distribuídos os 18 artigos científicos que compuseram este estudo. Destas publicações surgiram duas categorias importantes para a discussão, que são: as Barreiras sociais identificadas na vida das mulheres soropositivas e as Dificuldades assistenciais para as mulheres portadoras de HIV.

Quadro 2 - Distribuição dos artigos relacionados as barreiras sociais identificadas na vida das mulheres soropositivas, Aracaju/SE.

\begin{tabular}{|c|c|c|c|c|}
\hline Título do artigo & $\begin{array}{c}\text { Base de } \\
\text { dados }\end{array}$ & Região/Local & Método & Resultados \\
\hline $\begin{array}{c}\text { Aspectos que influenciam } \\
\text { o autocuidado de pacientes } \\
\text { vivendo com vírus da } \\
\text { imunodeficiência humana. }\end{array}$ & SCIELO & $\begin{array}{c}\text { Ribeirão Preto/ São Paulo- } \\
\text { Região Sudeste. }\end{array}$ & $\begin{array}{c}\text { Estudo transversal de } \\
\text { caráter analítico, com } \\
\text { abordagem quantitativa. }\end{array}$ & $\begin{array}{c}\text { Alteração da vida sexual, sentimentos } \\
\text { de solidão, tristeza e angústia. }\end{array}$ \\
\hline $\begin{array}{c}\text { HIV/AIDS e a ética do } \\
\text { cuidado a partir da } \\
\text { experiência de mulheres } \\
\text { ativistas no Rio de } \\
\text { Janeiro. }\end{array}$ & LILACS & $\begin{array}{c}\text { Rio de Janeiro- Região } \\
\text { Sudeste. }\end{array}$ & $\begin{array}{c}\text { Estudo qualitativo } \\
\text { desenvolvido a partir dos } \\
\text { fundamentos do } \\
\text { interacionismo simbólico. }\end{array}$ & $\begin{array}{c}\text { Implicação para o relacionamento a } \\
\text { dois, dificuldade de revelação do } \\
\text { diagnóstico principalmente ao } \\
\text { parceiro, gestão do risco sexual, } \\
\text { dificuldade de inserção no mercado de } \\
\text { trabalho. }\end{array}$ \\
\hline $\begin{array}{c}\text { O cuidado à pessoa que } \\
\text { vive com HIV/AIDS na } \\
\text { atenção primária à saúde. }\end{array}$ & SCIELO & $\begin{array}{c}\text { Florianópolis, Santa } \\
\text { Catarina- Região Sul. }\end{array}$ & $\begin{array}{c}\text { Pesquisa qualitativa, } \\
\text { exploratória e descritiva. }\end{array}$ & $\begin{array}{c}\text { Fragilidade diante do impacto do } \\
\text { diagnóstico de HIV, estigma, } \\
\text { preconceito social, angustia, medo e } \\
\text { taxação de diagnóstico da morte. }\end{array}$ \\
\hline
\end{tabular}




\begin{tabular}{|c|c|c|c|c|}
\hline $\begin{array}{l}\text { Iniquidades de gênero: } \\
\text { mulheres com HIV/Aids } \\
\text { em situação de violência. }\end{array}$ & LILACS & $\begin{array}{l}\text { Rio Grande do Sul- Região } \\
\text { Sul. }\end{array}$ & Estudo qualitativo. & $\begin{array}{c}\text { Sofrimento, destratamento pela } \\
\text { sociedade, relatos de violências, } \\
\text { abusos, preconceitos, estigmas, } \\
\text { infrações de direitos, desigualdades de } \\
\text { raça, classe social e gênero que foram } \\
\text { situações evidenciadas geradoras de } \\
\text { vulnerabilidades, violências e } \\
\text { iniquidades na vida de mulheres com } \\
\text { HIV/aids. }\end{array}$ \\
\hline $\begin{array}{l}\text { Nem santa, nem puta, } \\
\text { apenas mulher: a } \\
\text { feminização do HIV/aids e } \\
\text { a experiência de } \\
\text { soropositividade. }\end{array}$ & LILACS & $\begin{array}{l}\text { Recife- Pernambuco- Região } \\
\text { Nordeste. }\end{array}$ & $\begin{array}{c}\text { Trata-se de uma pesquisa } \\
\text { de campo, de abordagem } \\
\text { qualitativa. }\end{array}$ & $\begin{array}{c}\text { Fragilidade da relação conjugal, } \\
\text { desigualdade de gênero, falta do uso } \\
\text { do preservativo, sentimento de ódio e } \\
\text { revolta. }\end{array}$ \\
\hline $\begin{array}{c}\text { Representações sociais de } \\
\text { mulheres frente a } \\
\text { descoberta do diagnóstico } \\
\text { do HIV. }\end{array}$ & BVS & Alagoas- Região Nordeste. & $\begin{array}{l}\text { Estudo descritivo, } \\
\text { exploratório com } \\
\text { abordagem qualitativa. }\end{array}$ & $\begin{array}{l}\text { Angústia, medo, tristeza, terror, } \\
\text { surpresa, incredibilidade, solidão, } \\
\text { isolamento no trabalho, injustiça e } \\
\text { vergonha. Sentimento de traição pelo } \\
\text { parceiro, prejulgamento da sociedade. }\end{array}$ \\
\hline $\begin{array}{l}\text { Dificuldades do viver com } \\
\text { HIV/Aids: Entraves na } \\
\text { qualidade de vida. }\end{array}$ & SCIELO & $\begin{array}{l}\text { Ribeirão Preto, São Paulo- } \\
\text { Região Sudeste. }\end{array}$ & $\begin{array}{c}\text { Estudo descritivo, } \\
\text { exploratório, de abordagem } \\
\text { qualitativa desenvolvido } \\
\text { em Serviços de } \\
\text { Atendimento } \\
\text { Especializado. } \\
\end{array}$ & $\begin{array}{c}\text { Preconceito no núcleo familiar, } \\
\text { preconceito pela sociedade, } \\
\text { fragilidade que permeia a intimidade } \\
\text { afetivo-sexual, mudanças e } \\
\text { dificuldades físicas, sociais e } \\
\text { psíquicas. }\end{array}$ \\
\hline $\begin{array}{c}\text { Sintomas físicos e } \\
\text { psicológicos do estresse } \\
\text { em pessoas vivendo com o } \\
\text { vírus da imunodeficiência } \\
\text { humana. }\end{array}$ & LILACS & Região Sudeste. & $\begin{array}{l}\text { Estudo analítico de corte } \\
\text { transversal realizado em } \\
\text { cinco serviços de } \\
\text { atendimento especializado } \\
\text { para o atendimento ao } \\
\text { soropositivo. }\end{array}$ & $\begin{array}{l}\text { Predomínio de sinais e sintomas de } \\
\text { estresse nas mulheres soropositivas do } \\
\text { que com os homens, problemas com a } \\
\text { memória, mal-estar generalizado, } \\
\text { cansaço constante, impossibilidade de } \\
\text { trabalhar, vontade de fugir de tudo } \\
\text { diante das diversas responsabilidades } \\
\text { que as mulheres assumem. }\end{array}$ \\
\hline $\begin{array}{l}\text { Repercussões do HIV no } \\
\text { cotidiano de mulheres } \\
\text { vivendo com aids. }\end{array}$ & BVS & Bahia- Região Nordeste. & $\begin{array}{c}\text { Pesquisa qualitativa } \\
\text { realizada em um centro de } \\
\text { Informações em } \\
\text { DST/HIV/AIDS e } \\
\text { Hepatites Virais. }\end{array}$ & $\begin{array}{c}\text { Redução das relações sexuais, } \\
\text { aumento da responsabilidade pessoal } \\
\text { e social após o diagnóstico, } \\
\text { surgimento de sentimentos negativos } \\
\text { e positivos, busca por formas de } \\
\text { enfrentamento da doença. }\end{array}$ \\
\hline $\begin{array}{l}\text { Vítimas e culpadas: } \\
\text { representações sociais } \\
\text { sobre mulheres que vivem } \\
\text { com HIV. }\end{array}$ & LILACS & Belém-Pará -Região Norte. & $\begin{array}{l}\text { Trata-se de um estudo de } \\
\text { natureza exploratória, } \\
\text { descritiva, com abordagem } \\
\text { qualitativa realizado em } \\
\text { três serviços de saúde que } \\
\text { atendem pessoas vivendo } \\
\text { com HIV e são referência } \\
\text { em infecções sexualmente } \\
\text { transmissíveis e HIV. }\end{array}$ & $\begin{array}{l}\text { Falta do uso do preservativo, falta de } \\
\text { apoio do marido no enfrentamento, } \\
\text { sentimento de culpa, julgamento } \\
\text { social e pelos próprios profissionais. }\end{array}$ \\
\hline $\begin{array}{l}\text { Mulheres com HIV: } \\
\text { percepção sobre uma } \\
\text { futura gestação. }\end{array}$ & LILACS & Belém- Pará- Região Norte. & $\begin{array}{l}\text { Trata-se de um estudo } \\
\text { qualitativo, descritivo, tipo } \\
\text { explicativo, realizado em } \\
\text { uma unidade de referência } \\
\text { especializada no } \\
\text { atendimento ao paciente } \\
\text { soropositivo. }\end{array}$ & $\begin{array}{l}\text { Julgamento social, a soropositividade } \\
\text { como barreira para realizar o desejo } \\
\text { de engravidar. }\end{array}$ \\
\hline $\begin{array}{c}\text { Aids como doença do } \\
\text { outro: uma análise da } \\
\text { vulnerabilidade feminina. }\end{array}$ & BVS & $\begin{array}{l}\text { Rio de Janeiro- Região } \\
\text { Sudeste. }\end{array}$ & $\begin{array}{c}\text { Pesquisa descritiva, } \\
\text { qualitativa. }\end{array}$ & $\begin{array}{l}\text { Falta do uso do preservativo, maior } \\
\text { número de parceiros, uso de drogas } \\
\text { lícitas e ilícitas, sexo banalizado, } \\
\text { infidelidade do parceiro (a), o tabu, a } \\
\text { vergonha. }\end{array}$ \\
\hline $\begin{array}{l}\text { Mudanças no Cotidiano de } \\
\text { Mulheres Vivendo Com } \\
\text { Hiv: Análise Ambulatorial, } \\
\text { Rj, Brasil. } \\
\end{array}$ & BVS & $\begin{array}{l}\text { Rio de Janeiro- Região } \\
\text { Sudeste. }\end{array}$ & $\begin{array}{l}\text { Estudo descritivo e } \\
\text { prospectivo, com } \\
\text { abordagem qualitativa. }\end{array}$ & $\begin{array}{l}\text { Perda de relacionamento familiar e } \\
\text { relacionamentos afetivos, trabalho, } \\
\text { rotina diária, discriminação, ameaça } \\
\text { da perda do emprego. }\end{array}$ \\
\hline $\begin{array}{l}\text { Infecção pelo HIV em } \\
\text { adolescentes do sexo } \\
\text { feminino: um estudo } \\
\text { qualitativo. }\end{array}$ & LILACS & $\begin{array}{l}\text { Rio de Janeiro- Região } \\
\text { Sudeste. }\end{array}$ & $\begin{array}{l}\text { Estudo qualitativo, } \\
\text { realizado em quatro } \\
\text { hospitais públicos. }\end{array}$ & $\begin{array}{l}\text { Negação do diagnóstico, tristeza, } \\
\text { sentimentos depressivos, preconceito, } \\
\text { discriminação, exposição da } \\
\text { soropositividade no dia a dia. }\end{array}$ \\
\hline $\begin{array}{l}\text { Trajetórias de mulheres } \\
\text { vivendo com HIV/aids no } \\
\text { Brasil. Avanços e } \\
\text { permanências da resposta à } \\
\text { epidemia. }\end{array}$ & SCIELO & $\begin{array}{l}\text { Belém- Região Norte, } \\
\text { Goiânia Região Centro- } \\
\text { Oeste, Porto Alegre- Região } \\
\text { Sul, Pelotas- Região Sul } \\
\text { Recife- Região Nordeste, } \\
\text { Ribeirão Preto- Região } \\
\text { Sudeste. } \\
\end{array}$ & $\begin{array}{l}\text { Os dados analisados neste } \\
\text { artigo são oriundos de um } \\
\text { estudo mais amplo. }\end{array}$ & $\begin{array}{c}\text { Restringimento do círculo de } \\
\text { amizades, das atividades sociais e de } \\
\text { lazer, demissão do emprego, vida } \\
\text { sexual afetada, interrupção da vida } \\
\text { reprodutiva. }\end{array}$ \\
\hline
\end{tabular}

Fonte: Autores (2021). 
Quadro 3 - Distribuição dos artigos referentes as dificuldades assistenciais para as mulheres portadoras de HIV, Aracaju/SE.

\begin{tabular}{|c|c|c|c|c|}
\hline Título do artigo & $\begin{array}{c}\text { Base de } \\
\text { dados }\end{array}$ & Região/Local & Método & Resultados \\
\hline $\begin{array}{l}\text { Representações e } \\
\text { práticas de cuidado de } \\
\text { profissionais de saúde às } \\
\text { pessoas com HIV. }\end{array}$ & LILACS & $\begin{array}{l}\text { Recife- } \\
\text { Pernambuco- } \\
\text { Região } \\
\text { Nordeste. }\end{array}$ & $\begin{array}{l}\text { Estudo descritivo, } \\
\text { exploratório, de } \\
\text { abordagem } \\
\text { qualitativa. }\end{array}$ & $\begin{array}{l}\text { Demanda para o atendimento maior que a } \\
\text { oferta prejudicando a assistência, déficit de } \\
\text { área física para atendimento da demanda, } \\
\text { falta de equipe multiprofissional suficiente } \\
\text { para atender a toda a demanda, falta de } \\
\text { contratação de profissionais capacitados para } \\
\text { atuar nesses serviços especializados, no } \\
\text { planejamento e na gestão. }\end{array}$ \\
\hline $\begin{array}{l}\text { O cuidado à pessoa que } \\
\text { vive com HIV/AIDS na } \\
\text { atenção primária à } \\
\text { saúde. }\end{array}$ & SCIELO & $\begin{array}{l}\text { Florianópolis, } \\
\text { Santa } \\
\text { Catarina- } \\
\text { Região Sul. }\end{array}$ & $\begin{array}{l}\text { Pesquisa qualitativa, } \\
\text { exploratória e } \\
\text { descritiva. }\end{array}$ & $\begin{array}{c}\text { Dificuldade em revelar o diagnóstico ao } \\
\text { paciente devido a ansiedade do profissional e } \\
\text { falta de preparo. Sigilo do diagnóstico. } \\
\text { Desconhecimento do real papel da área } \\
\text { assistencial, principalmente do enfermeiro } \\
\text { frente ao paciente soropositivo sendo uma } \\
\text { atuação de baixa visibilidade. } \\
\text { O cuidado aos portadores de HIV/aids se } \\
\text { caracterizam ainda por uma atenção } \\
\text { médico/centrada e há inexistência de um } \\
\text { fluxo formal para o acompanhamento desses } \\
\text { portadores. }\end{array}$ \\
\hline $\begin{array}{l}\text { Dificuldades do viver } \\
\text { com HIV/Aids: Entraves } \\
\text { na qualidade de vida. }\end{array}$ & SCIELO & $\begin{array}{l}\text { Ribeirão } \\
\text { Preto, São } \\
\text { Paulo- } \\
\text { Região } \\
\text { Sudeste. }\end{array}$ & $\begin{array}{l}\text { Estudo descritivo, } \\
\text { exploratório, de } \\
\text { abordagem } \\
\text { qualitativa. }\end{array}$ & $\begin{array}{l}\text { Necessidade em edificar um cuidado integral } \\
\text { que atenda às necessidades das pessoas que } \\
\text { vivem com HIV/Aids, dificuldade do } \\
\text { profissional em compreender o cuidado como } \\
\text { um todo, necessidade de avaliar os fatores } \\
\text { associados a dificuldade da adesão a Terapia } \\
\text { Antirretroviral (TARV), enfoque da } \\
\text { assistência somente em processos } \\
\text { biomédicos. }\end{array}$ \\
\hline $\begin{array}{l}\text { Representações sociais } \\
\text { de mulheres frente a } \\
\text { descoberta do } \\
\text { diagnóstico do HIV. }\end{array}$ & BVS & $\begin{array}{l}\text { Alagoas- } \\
\text { Região } \\
\text { Nordeste. }\end{array}$ & $\begin{array}{l}\text { Estudo descritivo, } \\
\text { exploratório com } \\
\text { abordagem } \\
\text { qualitativa. }\end{array}$ & $\begin{array}{c}\text { Dificuldade no processo de aceitação do } \\
\text { diagnóstico e enfrentamento da } \\
\text { soropositividade. }\end{array}$ \\
\hline $\begin{array}{l}\text { Cuidado de enfermagem } \\
\text { em Serviço } \\
\text { Ambulatorial } \\
\text { Especializado em } \\
\text { HIV/Aids. }\end{array}$ & SCIELO & $\begin{array}{c}\text { Brasília - } \\
\text { Região } \\
\text { Centro-Oeste. }\end{array}$ & $\begin{array}{c}\text { Trata-se de uma } \\
\text { pesquisa exploratória } \\
\text { descritiva com } \\
\text { abordagem qualitativa } \\
\text { realiza danos Serviços } \\
\text { Ambulatoriais } \\
\text { Especializados em } \\
\text { HIV/Aids. } \\
\end{array}$ & $\begin{array}{l}\text { Dificuldade de dar seguimento às consultas } \\
\text { de enfermagem, que é responsável por } \\
\text { esclarecer e reforçar todas as orientações do } \\
\text { tratamento do HIV, porém o paciente } \\
\text { frequentemente não retorna para as mesmas. } \\
\text { Limitação do tratamento de HIV apenas ao } \\
\text { diagnóstico e a terapia medicamentosa. }\end{array}$ \\
\hline $\begin{array}{l}\text { A oferta do teste anti- } \\
\text { HIV às usuárias das } \\
\text { unidades da rede básica } \\
\text { de saúde: diferentes } \\
\text { abordagens dos } \\
\text { profissionais. }\end{array}$ & BVS & $\begin{array}{l}\text { Rio de } \\
\text { Janeiro- } \\
\text { Região } \\
\text { Sudeste. }\end{array}$ & $\begin{array}{c}\text { É um estudo } \\
\text { descritivo, qualitativo. }\end{array}$ & $\begin{array}{l}\text { Oferta de forma inadequada do teste anti- } \\
\text { HIV, falta de esclarecimento e } \\
\text { aconselhamento na assistência. }\end{array}$ \\
\hline $\begin{array}{l}\text { Vítimas e culpadas: } \\
\text { representações sociais } \\
\text { sobre mulheres que } \\
\text { vivem com HIV. }\end{array}$ & LILACS & $\begin{array}{l}\text { Belém-Pará- } \\
\text { Região Norte. }\end{array}$ & $\begin{array}{l}\text { Trata-se de um estudo } \\
\text { de natureza } \\
\text { exploratória, } \\
\text { descritiva, com } \\
\text { abordagem qualitativa } \\
\text { realizado em três } \\
\text { serviços de saúde que } \\
\text { atendem pessoas } \\
\text { vivendo com HIV e } \\
\text { são referência em } \\
\text { infecções sexualmente } \\
\text { transmissíveis e HIV. }\end{array}$ & $\begin{array}{l}\text { O risco da transmissão vertical, julgamento } \\
\text { errôneo, representações negativas dos } \\
\text { próprios profissionais da assistência, } \\
\text { principalmente em casos de soropositivas } \\
\text { grávidas. }\end{array}$ \\
\hline $\begin{array}{l}\text { Mulheres com HIV: } \\
\text { percepção sobre uma } \\
\text { futura gestação. }\end{array}$ & LILACS & $\begin{array}{l}\text { Belém- Pará- } \\
\text { Região Norte. }\end{array}$ & $\begin{array}{l}\text { Trata-se de um estudo } \\
\text { qualitativo, descritivo, } \\
\text { tipo explicativo, } \\
\text { realizado em uma } \\
\text { unidade de referência }\end{array}$ & $\begin{array}{l}\text { Receio da transmissão vertical, falta de } \\
\text { orientação da assistência às soropositivas } \\
\text { sobre a possibilidade de gestar com os riscos } \\
\text { diminuídos da transmissão vertical do HIV. }\end{array}$ \\
\hline
\end{tabular}




\begin{tabular}{|c|c|c|c|c|}
\hline & & & $\begin{array}{c}\text { especializada no } \\
\text { atendimento ao } \\
\text { paciente soropositivo. }\end{array}$ & $\begin{array}{l}\text { A não adesão ou o abandono do tratamento, } \\
\text { dificuldades da utilização do medicamento, } \\
\text { não aceitação do diagnóstico, reações } \\
\text { medicamentosas. Carência de linhas de } \\
\text { cuidados voltados para mulheres que vivem } \\
\text { com HIV/Aids, ligadas à reprodução e } \\
\text { sexualidade. }\end{array}$ \\
\hline $\begin{array}{l}\text { Mudanças no Cotidiano } \\
\text { de Mulheres Vivendo } \\
\text { Com Hiv: Análise } \\
\text { Ambulatorial, }\end{array}$ & BVS & $\begin{array}{l}\text { Rio de } \\
\text { Janeiro- } \\
\text { Região } \\
\text { Sudeste. }\end{array}$ & $\begin{array}{l}\text { É um estudo } \\
\text { descritivo e } \\
\text { prospectivo, com } \\
\text { abordagem qualitativa } \\
\text { realizado em um } \\
\text { ambulatório de } \\
\text { imunologia. } \\
\end{array}$ & $\begin{array}{l}\text { Dificuldades na adesão ao antirretroviral } \\
\text { relacionado aos efeitos adversos, alta } \\
\text { dosagem, as interações medicamentosas, } \\
\text { assistência inadequada durante as fases a } \\
\text { tratamento. }\end{array}$ \\
\hline $\begin{array}{l}\text { Infecção pelo HIV em } \\
\text { adolescentes do sexo } \\
\text { feminino: um estudo } \\
\text { qualitativo. }\end{array}$ & LILACS & $\begin{array}{c}\text { Rio de } \\
\text { Janeiro- } \\
\text { Região } \\
\text { Sudeste. }\end{array}$ & $\begin{array}{l}\text { Estudo qualitativo, } \\
\text { realizado em quatro } \\
\text { hospitais públicos. }\end{array}$ & $\begin{array}{c}\text { Limitações impostas na vida de pacientes } \\
\text { jovens soropositivas, pela obrigatoriedade de } \\
\text { tomar os remédios do tratamento, } \\
\text { diariamente. O receio frente à } \\
\text { impossibilidade de realizar o desejo de } \\
\text { maternidade. }\end{array}$ \\
\hline
\end{tabular}

Fonte: Autores (2021).

\section{Discussão}

\subsection{Barreiras sociais identificadas na vida da soropositiva.}

A descoberta do HIV é caracterizada pelas mulheres por sentimentos negativos, como medo, tristeza, surpresa, depressão, incredulidade, injustiça e vergonha. O diagnóstico desperta o sentimento de indignação, raiva por sentir-se traída pelo parceiro íntimo evidenciando dessa forma a vulnerabilidade da mulher pela submissão e afetividade intensa ao companheiro. A maioria perde a auto estima, e tem dificuldades de ser inserida no mercado de trabalho (Taquette, Rodigues, \& Bortolotti, 2015).

As repercussões do HIV na vida das mulheres acometem a alteração da vivência sexual, restringimento do círculo de amizades, atividades sociais, lazer, e na relação familiar. Além de constrangimento como no cotidiano das jovens soropositivas, que acabam sofrendo denúncia da soropositividade com o uso do cartão de gratuidade no ônibus, necessidade de tomar os medicamentos em horários certos também as obriga a revelar sua condição de saúde entre outras situações que expõe ao julgamento (Alencar et al., 2019).

Considerado o diagnóstico uma declaração de morte, no cenário social, relaciona-se a existência de muito estigma e preconceito da sociedade, gerando muita angústia e medo aos soropositivos. O impacto de viver com a doença ainda é o maior obstáculo. Pessoas os veem como "contaminados" ou "condenados", limitando seu suporte social e a inserção ou relação no ambiente de trabalho promovendo o receio em revelar seu diagnóstico inclusive para a própria família (Angelim et al., 2019).

Por isso, as manifestações de sintomas psicológicos do estresse e da depressão são mais frequentes nas mulheres, pressupondo as responsabilidades que elas assumem, gerando inclusive sofrimento emocional, depressão do sistema imunológico que facilita o desenvolvimento da AIDS (Melo et al., 2019). No entanto, a tríade "família, filhos e amigos" é considerada base de sustentação, e quando esta não está presente na vida do portador de HIV, tem maiores repercussões negativas que impactam diretamente no processo de enfrentamento da soropositividade (Jesus et al., 2017).

Por conta disso, muitas mulheres mascaram o diagnóstico no ambiente de trabalho devido ao receio do prejulgamento e como uma tentativa de manter-se empregada. No entanto, a Lei No. 12.984 / 2014 define como discriminação, crime punível com prisão e multa, aqueles que negam emprego a pessoa que vive com HIV (PVHIV), que faz segregação no ambiente de trabalho (Souza et al.,2019).

A feminização do HIV mostrou mudanças de perfil das portadoras que antes era comum em mulheres usuárias de drogas injetáveis, hemofílicos, homens bissexuais ou profissionais do sexo. Atualmente, as mesmas são as mais contaminadas, com práticas heterossexuais, parceiros fixos e em relações estáveis. No entanto, ainda há a não aceitação da condição sorológica, 
induzida na noção de que a AIDS é uma doença que acarreta somente aqueles que desviam das normas na sexualidade se colocando em risco (Vargens, 2020).

A consolidação da vida conjugal através da estabilidade amorosa e sexual é considerada um fator preponderante na falta do uso do preservativo, pois o uso é visto, em sua maioria, com desconfiança na relação. Quanto maior o tempo de relação do casal, menor exigência do uso do preservativo, demonstrando que, para estes, a infecção pelo HIV está relacionada a pessoas que não estão em relacionamentos estáveis. Portanto, maior é a surpresa na descoberta do diagnóstico para as mulheres de relacionamento estável (Monteiro, 2018).

Há mulheres que ainda são vítimas da falta de autonomia na condução da vida sexual e reprodutiva, empoderando o homem a tomar a decisão do uso do preservativo e as práticas sexuais. Desse modo, retira a autonomia da mulher sobre seu corpo e sexualidade, aumentando a vulnerabilidade no risco de violência e de aquisição do HIV. Com isso, quando a mulher é diagnosticada, na maioria dos casos não tem o apoio do marido no enfrentamento e ainda são culpabilizadas pelos mesmos. Porém, quando o parceiro é diagnosticado com o HIV, ela oferta todo o apoio (Panarra et al., 2017).

E, nesse contexto da soropositividade na vida do casal, evidenciam-se alterações na frequência das relações, até a rejeição pelo parceiro influenciando na sexualidade da mulher, dentre elas a diminuição do desejo sexual, frente ao receio pelo risco da transmissão sexual, se sentindo alguém perigoso ao parceiro sexual, acabam perdendo a libido e demonstrando um sentimento de culpa (Lima, 2018).

\subsection{Dificuldades assistenciais para as mulheres portadoras de HIV.}

Na prática assistencial, o atendimento ao portador do vírus HIV é prejudicado, pois a demanda é maior do que a oferta. Diante disso, há a necessidade de uma equipe multiprofissional suficiente para atender a demanda, sendo essencial a ampliação do quantitativo pessoal com a contratação de profissionais capacitados para atuar nesses serviços especializados, no planejamento e na gestão. Essa ação deve promover uma aproximação entre a equipe de saúde e os usuários do sistema, oferecendo um serviço com acesso equitativo aos cuidados de saúde, garantindo aceitabilidade do serviço no contexto do HIV (Angelim et al., 2019).

Nesse mesmo contexto, a inexistência de um fluxo formal para o acompanhamento das PVHIV é outro problema evidente na assistência. Todavia, a atuação dos profissionais demonstra um perfil de engajamento e proximidade com as pessoas que vivem com AIDS, por meio das tecnologias de trabalho (Colaço et al., 2019). É preciso que os profissionais de saúde, em especial a equipe de enfermagem, devido a suas funções de cuidador, educador em saúde, criem intervenções na qualidade de vida dos soropositivos instituindo um cuidado integral (Jesus et al., 2017).

A lógica de atendimento aos portadores de HIV ainda circunda em torno da medicalização e da atuação médica. Com essa abordagem, evidencia-se a necessidade de retorno do paciente ao atendimento com o enfermeiro como forma de que as orientações técnicas acerca da patologia sejam reforçadas, assim como supervisionar se estas estão sendo adequadamente seguidas. No entanto, na realidade esse retorno em sua maioria não ocorre e esse resultado demonstra que a atuação ainda é de baixa visibilidade, apontado um desconhecimento do real papel do enfermeiro frente às questões relacionadas ao HIV/aids (Macêdo, 2016 \& Colaço, 2019).

Os profissionais de saúde, em especial o enfermeiro, que é o agente catalizador da atenção multiprofissional nos Centros de Saúde, condutor das ações de diagnóstico do HIV, aconselhamento, acompanhamento, promoção e monitoramento da adesão à Terapia Anti-Retroviral (TARV) percebem o momento da revelação do diagnóstico como uma ocasião geradora de grande ansiedade para ambos os sujeitos e que há necessidade de preparo do profissional para agir nesse momento, por isso é importante a qualificação dos profissionais e dos cuidados aos portadores de HIV (Colaço et al., 2019). 
No entanto muitos pacientes preferem ocultar o diagnóstico, por vergonha, medo do preconceito, consequentemente, o seu encobrimento leva à falta pela busca do atendimento nos Centros de Saúde mais próximos à residência, acarretando falta do autocuidado (Lobo et al., 2018).

A oferta inadequada do teste anti-HIV é outra problemática presente na assistência, juntamente com a falta do aconselhamento adequado, pois não há uniformidade sobre o conteúdo e a presença de todos componentes dessa prática que geralmente é realizada na assistência à saúde da mulher inclusive no pré-natal (Marques et al., 2015). Além disso, a obrigatoriedade de tomar remédios todos os dias e de ir ao médico regularmente impõe limitações e faz com que a paciente se lembre cotidianamente de que tem uma doença, levando à autocensura pelo sexo sem proteção (Taquette, Rodrigues, \& Bortolotti, 2015).

Portanto, a dificuldade em aderir à Terapia Antirretroviral está relacionada também à utilização do medicamento, ao número de comprimidos, a seus efeitos adversos, às dosagens incompatíveis com as atividades diárias do paciente e às interações medicamentosas. Sendo assim, é preciso analisar os fatores associados a essa adesão para o aprimoramento da efetividade do tratamento que também depende da atuação da assistência (Souza et al., 2019).

O risco da transmissão vertical é outra barreira encontrada na vida da mulher soropositiva principalmente quando esta tem o desejo de ser mãe. Este é um dos principais problemas e preocupações evidenciados nas vidas de soropositivas pelo receio de ser considerada culpada por transmitir o vírus para o seu próprio filho (Rodrigues et al., 2020). Por essa razão, a mulher tornase um ser frustrado por não poder construir uma família por causa da doença devido ao medo de ser rejeitada pelos possíveis parceiros em função da doença e às incertezas em relação à possibilidade de ter filhos (Taquette, Rodrigues, \& Bortolotti, 2015).

Infelizmente, além de ser julgada pela sociedade e até pela família, a mulher portadora de HIV sofre julgamento na assistência por parte de alguns profissionais, transparecendo uma postura totalmente errônea e desumana. Infelizmente, ocorre ainda mais com frequência nos casos de mulheres soropositivas quando engravidam e o seu filho é contaminado, é considerada por alguns como uma gestante que não teve cuidado com a saúde durante o ciclo gravídico-puerperal (Panarra et al., 2017).

Há casos em que os profissionais chegam até a exaltar uma esterilização coletiva sem dar os direitos à mulher a escolha de gestar uma criança. O contexto inserido no ato de esterilizar aparece como solução para impedir a gestação mesmo que todos os envolvidos saibam que esta mulher pode ter filhos com reduzido risco de contaminação, caso seja acompanhada durante o ciclo gravídico-puerperal da forma adequada (Panarra et al., 2017).

Entretanto, sabe-se que muitas mulheres ainda desconhecem essa possibilidade de ser mãe frente ao diagnóstico de portabilidade do HIV, portanto faz-se que os serviços de saúde promovam um ambiente que apoie a gravidez e desenvolvam linhas de cuidados voltados para mulheres que vivem com HIV/Aids, considerando suas perspectivas ligadas à reprodução e a sua sexualidade, abraçando oportunidades para apoiar a mãe soropositiva a atingir seus objetivos de fertilidade (Rodrigues et al., 2020).

\section{Considerações Finais}

Diante do objetivo proposto para o estudo, revelou-se que o diagnóstico de HIV é recebido com grande impacto pela mulher, apresentando diferentes sentimentos no momento da descoberta. Além do estigma, enfrentado por elas, que levam a uma mudança na maneira de viver no contexto social, sexual, afetivo e familiar, dificultando o enfrentamento da soropositividade. É necessária uma assistência multiprofissional capacitada para prestar os cuidados aos portadores de HIV de modo holístico, atendendo a toda a demanda.

A amostra desse estudo foi relativamente satisfatória para a pesquisa, pois é perceptível a falta de referenciais teóricos que abordem exclusivamente a assistência de saúde direcionadas ao público soropositivo feminino, portanto foi preciso ajustamento no eixo da temática. 
Considera-se que esse estudo possa colaborar no conhecimento sobre as dificuldades no enfretamento do HIV na vida das mulheres, que o tema proposto pelas autoras possa contribuir para as discussões e suscitar futuras pesquisas. Idealizando dessa forma uma melhora na qualidade de vida das soropositivas, na assistência multiprofissional, mais ampla, qualificada, reduzindo os entraves assistenciais e sociais.

\section{Referências}

Associação Brasileira de Normas Técnicas (2002). NBR 10520: informação e documentação: citações em documentos.

Associação Brasileira de Normas Técnicas (2002). NBR 6023: Informação e documentação: Referências.

Alencar, R. A. (2019). Aspectos que influenciam o autocuidado de pacientes vivendo com vírus da imunodeficiência humana Rev. Latino-Am. Enfermagem 1(27).

Angelim, R. C. M. (2019). Representações e práticas de cuidado de profissionais de saúde às pessoas com HIV. Rev. esc. enferm. USP, 53, e03478.

Benchetrit, A. G. (2018). Clinical and epidemiological features and chronic Trypanosoma Cruzi infection in patients with HIV/AIDS in Buenos Aires, Argentina.Inter Journ Infect Disea. 67, 118-121

Brasil. Ministério da Saúde. (2019). Aids / HIV: o que é, causas, sintomas, diagnóstico, tratamento e prevenção.

Brasil. Ministério da Saúde. (2019). Boletim Epidemiologico de Aids e DST HIV/Aids. Número Especial.

Brasil. Ministério da Saúde. (2019). Tratamento para o HIV.

Brasil. Ministério da Saúde (2019). Secretaria de Vigilância em Saúde. Boletim Epidemiológico HIV/Aids/2019. Brasília: Ministério da Saúde.

Cajado, L. C. S., \& Monteiro, S. (2018). HIV/AIDS e a ética do cuidado a partir da experiência de mulheres ativistas no Rio de Janeiro. Sex., Salud Soc. (Rio J.), 1(30), 183-200.

Colaço, A. D. (2019). O cuidado à pessoa que vive com HIV/AIDS na atenção primária à saúde. Texto Contexto Enferm.

Ceccon, R. F., \& Meneghel, S. N. (2017). Iniquidades de gênero: mulheres com HIV/Aids em situação de violência. Physis: Revista de Saúde Coletiva.

Ferenhof, H. A., \& Fernandes, R. F. (2016). Desmistificando a revisão de literatura como base para redação científica: método SSF. Revista ACB. 21(3), 550563.

Fialho, C. X. (2020). A atuação do enfermeiro frente à relação à gestante vivendo com HIV / Aids. Pesquisa, Sociedade e Desenvolvimento. 9(7), e892974545.

Jesus, G. J. (2017). Dificuldades do viver com HIV/Aids: Entraves na qualidade de vida. Revista Acta Paulista de Enfermagem. 30(3), $301-307$.

Lourenco, G. O., Amazonas, M. C. L. A., \& Lima, R. D. M. (2018). Nem santa, nem puta, apenas mulher: a feminização do HIV/aids e a experiência de soropositividade. Sex., Salud Soc. (Rio J.), 30,262-281.

Lobo, A. L. S. F. (2018). Mulheres representações sociais na cara para HIV diagnóstico divulgação. Rev Fundo Cuidados Online. 10(2), 334-342.

Macêdo, S. M. (2016). Cuidado de enfermagem em Serviço Ambulatorial Especializado em HIV/Aids. Revista. Brasileira de. Enfermagem. 69(3).

Marques, S. C. (2015). A oferta do teste anti-HIV às usuárias das unidades da rede básica de saúde: diferentes abordagens dos profissionais. Rj, Brasil. Rev Fund Care Online. 7(1), 1891-1904.

Melo, E. (2019). Sintomas físicos e psicológicos do estresse em pessoas vivendo com o vírus da imunodeficiência humana. Revista Portuguesa de Enfermagem de Saúde Mental. 22(1), 19-26.

Oliveira, A. D. F (2015). Repercussões do HIV no cotidiano de mulheres vivendo com aids._Revista de Pesquisa Cuidado é Fundamental Online. 7(1), 19751986.

Panarra, B. A. C. S. (2017). Vítimas e culpadas: representações sociais sobre mulheres que vivem com HIV. Rev Cuid. 8(3): 1887-98.

Rodrigues, J. P. (2020). Mulheres com HIV: percepção sobre uma futura gestação. Rev enferm UFPE on line. 14 , e244053.

Silva C. M., \& Vargens, O. M. C. (2015). Aids como doença do outro: uma análise da vulnerabilidade feminina. Rev Fund Care Online.2015. 7(4), 3125-3134.

Sousa, M. M. L. (2017). A Metodologia de Revisão Integrativa da Literatura em Enfermagem. Revista Investigação Em Enfermagem. 17-26.

Souza, F. B. A. (2019). Mudanças no Cotidiano de Mulheres Vivendo Com Hiv: Análise Ambulatorial, Rj, Brasil. Rev Fund Care Online. 1(8).

Taquette, S. R., Rodrigues, A. D., \& Bortolotti, L. R. (2015). Infecção pelo HIV em adolescentes do sexo feminino: um estudo qualitativo. Revista Panamericana de Salud Pública. 37, 324-329.

Villela, W. V., \& Barbosa, R. M. (2017). Trajetórias de mulheres vivendo com HIV/aids no Brasil. Avanços e permanências da resposta à epidemia. Ciência \& Saúde Coletiva. 22, 87-96. 